\title{
Circulating HER-2 mRNA in the peripheral blood as a potential diagnostic and prognostic biomarker in females with breast cancer
}

\author{
YANLIN WU ${ }^{1 *}$, QIPING MENG $^{2 *}$, ZHIXUE YANG $^{1 *}$, LILI SHI $^{2}$, RONGKUAN HU ${ }^{2}$, PEIZHUO ZHANG $^{2}$, \\ JINRONG WEI ${ }^{1}$, JIE REN ${ }^{1}$, BINGJING LENG ${ }^{1}$, DONG XU ${ }^{1}$ and GUO-QIN JIANG ${ }^{1}$ \\ ${ }^{1}$ Department of General Surgery, The Second Affiliated Hospital of Soochow University, Suzhou, Jiangsu 215004; \\ ${ }^{2}$ GenePharma Limited Liability Company, Suzhou, Jiangsu 215125, P.R. China
}

Received November 21, 2017; Accepted May 4, 2018

DOI: $10.3892 / \mathrm{ol} .2018 .9091$

\begin{abstract}
Breast cancer is a prevalent malignant cancer worldwide, and a lack of defined biomarkers for early prognostication contributes to its high associated mortality rate, especially in human epidermal growth factor receptor 2 (HER-2)-positive breast cancer. In the present study, HER-2 mRNA levels in patients were detected prior to surgery and during neoadjuvant chemotherapy to explore its potential diagnostic and prognostic value. Blood samples were collected from 70 patients with breast cancer, including 50 HER-2-negative and 20 HER-2-positive patients, prior to and following surgery (postoperative, $\mathrm{n}=13$; neoadjuvant chemotherapy, $\mathrm{n}=5$ ); the control group included 35 samples from healthy individuals. The relative mRNA level of HER-2 in blood was determined by one-step reverse transcription-quantitative polymerase chain reaction. HER-2 expression curves of measurements taken during neoadjuvant chemotherapy were compared with the tumor size. A significant difference in the blood HER-2 mRNA level was observed between healthy women and patients with breast cancer $(\mathrm{P}<0.0001)$. A cutoff value of 1.512 was established for the circulating HER-2 level in healthy subjects based on the upper $95 \%$ confidence interval value of samples from the control group. The level of HER-2 mRNA in blood was associated with the HER-2 status, Ki-67 expression, and lymphovascular invasion in primary tumor tissue samples; however, there was no association with the lymph node status, tumor stage, tumor grade, tumor size, patient age, estrogen or progesterone receptor status of the primary tumor. HER-2 mRNA levels were associated with the response rate, as determined by primary tumor size, in patients who received
\end{abstract}

Correspondence to: Professor Guo-Qin Jiang, Department of General Surgery, The Second Affiliated Hospital of Soochow University, 1055 San-Xiang Road, Suzhou, Jiangsu 215004, P.R. China E-mail: jiang_guoqin@163.com

*Contributed equally

Key words: breast cancer, human epidermal growth factor receptor-2, peripheral blood, neoadjuvant chemotherapy neoadjuvant chemotherapy. In conclusion, baseline and early changes in peripheral blood HER-2 mRNA indicated that HER-2 mRNA may be a potential diagnostic biomarker for breast cancer and a prognostic marker for predicting the efficacy of neoadjuvant therapy.

\section{Introduction}

Breast cancer is a significant health problem for women in China. According to the China Health Statistics Yearbook published in 2011, approximately 169,452 new patients with breast cancer were diagnosed and 44,908 breast cancer-associated mortalities occurred in China in 2008; furthermore, these numbers accounted for $12.2 \%$ of all newly diagnosed breast cancer cases and $9.6 \%$ of all mortalities from breast cancer worldwide $(1,2)$. Therefore, it is important to identify predictive and prognostic factors for breast cancer, and to assess their potential impact for treatment selection. The discovery of human epidermal growth factor receptor 2 (HER-2)/neu gene amplification and its association with poor prognosis and an aggressive tumor phenotype has improved our understanding of the prognosis and therapeutic management of patients with breast cancer $(3,4)$.

The HER-2/neu gene is an oncogene located on chromosome 17 that encodes HER-2/neu, a transmembrane glycoprotein with tyrosine kinase activity from the epidermal growth factor receptor family (5). In $\sim 20 \%$ of patients with invasive breast cancer, the HER-2/neu gene is amplified or overexpressed (6,7). It can activate cellular signaling pathways such as PI3K-Akt and Ras-MAPK, leading to cell proliferation, growth, and survival (8). The amplification of HER-2 is associated with a poor prognosis, metastasis, chemoresistance, and an aggressive tumor phenotype (9). Trastuzumab, a recombinant humanized monoclonal antibody against HER-2, improves the survival of patients with HER-2-overexpressing tumors $(10,11)$. However, in clinical practice, the definition of primary tumor HER-2 overexpression in breast cancer patients is controversial. In certain patients with primary trastuzumab resistance, HER-2 expression in the peripheral blood after primary tumor resection is difficult to detect. In rescue treatments for metastatic breast cancer, the anti-HER-2 therapies are ineffective in a proportion of the patients. In addition, biopsy results for certain types of metastasis are often unavailable, 
and the HER-2 status cannot be determined. Furthermore, the use of anti-HER-2 treatments based on primary tumor HER-2 status is not adequate because of the treatment delay $(12,13)$. Therefore, the identification of an indicator for the real-time monitoring of HER-2 status is urgently required.

In clinical practice, the main methods currently used to determine tissue HER-2 status are immunohistochemistry (IHC) and fluorescence in situ hybridization (FISH) (14). Only tumors with scores of $2+$ or $3+$ with a FISH ratio $\geq 2.0$ are defined as HER-2-positive (15). In addition to determining HER-2 status in tissue specimens, there has been a high level of interest in liquid biopsy to determine the level of circulating HER-2, due to its accessibility and the possibility for the serial monitoring of the tumor response to therapy (16). The detection of HER-2 mRNA-positive circulating tumor cells (CTCs) in peripheral blood is considered a useful tool in the early diagnosis of breast cancer, and an independent prognostic factor for disease-free survival (DFS) (17,18). A number of previous studies have indicated that HER-2 mRNA in the peripheral blood of patients with breast cancer can be detected by reverse transcription-quantitative polymerase chain reaction (RT-qPCR), and that the detected levels were consistent with HER-2 status determined by IHC (19-21). To the best of our knowledge, a cutoff value for HER-2 mRNA as a marker of breast cancer has not been determined to date. Changes in the HER-2 mRNA level in peripheral blood may provide information for the selection of adequate therapeutic regimens, especially in patients exhibiting a poor response to chemotherapy.

In the present study, one-step RT-qPCR was used to detect circulating HER-2 mRNA, in order to determine its efficacy in indicating HER-2 expression status in breast cancer. The main aim of the present study was to determine the HER-2 mRNA status in the peripheral blood of patients with breast cancer prior to surgery and healthy individuals, to assess its potential diagnostic value in patients with breast cancer. For this purpose, we established an exact cutoff for HER-2 mRNA as a marker of breast cancer. In addition, the present study investigated whether the HER-2 mRNA level in the peripheral blood could predict the efficacy of neoadjuvant chemotherapy without trastuzumab.

\section{Materials and methods}

Patients. Peripheral blood was obtained from 70 patients with breast cancer without distant metastases, and 35 healthy control subjects (median age is 52 years, age range: 27 to 82 years, female, with no history of breast cancer at the Second Affiliated Hospital of Soochow University (Suzhou, China) between August 2016 and August 2017.All patients who participated in this study signed a document of informed consent. Study approval was obtained from the independent ethics committee at the Second Affiliated Hospital of Soochow University (Suzhou, China). The privacy of the patients involved was protected.

Patient characteristics. This study included 70 women with breast cancer, with a median age of 52 years (range: 27-82 years). The pathology type was invasive ductal carcinoma for all patients. The distribution of tumor sizes $(\mathrm{T})$ was as follows: $42.9 \%(\mathrm{n}=30)$ T1 $(\leq 2 \mathrm{~cm}), 54.3 \%(\mathrm{n}=38)$ T2 $(>2 \mathrm{~cm}$ and $<5 \mathrm{~cm})$, and $2.8 \%(\mathrm{n}=2) \mathrm{T} 3(\geq 5 \mathrm{~cm})$. Lymph node status was negative in $41.4 \%(n=29)$, positive in $50 \%(n=35)$, and unknown in $8.6 \%(n=6)$ of the patients. According to the World Health Organization grading system $(22,23), 74.3 \%(n=52)$ of tumors were well differentiated (grade I) and/or moderately differentiated (grade II), $10 \%(n=7)$ were poorly differentiated (grade III), and $15.7 \%(n=11)$ were of unknown differentiation. None of the patients had distant metastases; $24.3 \%(n=17)$ had stage I cancer, $41.4 \%(n=29)$ had stage II, $21.4 \%(n=15)$ had stage III, and $12.9 \%(n=9)$ had an unknown cancer status. Clinical and pathological characteristics of the patients are listed in Table I. Among the 95 blood samples isolated from the patients with breast cancer, $70(73.7 \%)$ were from preoperative patients, $13(13.7 \%)$ were from postoperative patients without adjuvant therapy, and $12(12.6 \%)$ were from patients receiving neoadjuvant therapy.

Neoadjuvant therapy. Three cycles of docetaxel $\left(75 \mathrm{mg} / \mathrm{m}^{2}\right.$ on day 1 every 3 weeks), followed by three cycles of FEC (5'-fluorouracil $500 \mathrm{mg} / \mathrm{m}^{2}$, epirubicin $75 \mathrm{mg} / \mathrm{m}^{2}$, and cyclophosphamide $600 \mathrm{mg} / \mathrm{m}^{2}$ on day 1 every 3 weeks).

MRI assessment. A total of 5 patients with confirmed breast cancer underwent MRI examinations at GE Signa Excite HD 3.0T scanner. All breast MRI scans were confirmed by two consultant radiologists, and where there was discordance the images were reviewed by a third consultant radiologist. The schedule of imaging was: Prior to antitumor treatment (time point zero; TP0), after three treatment cycles (TP3), and after six treatment cycles (TP6). However, due to the small sample of biopsy samples, the tissue sub-type could not be determined.

Sample collection. Peripheral blood $(5 \mathrm{ml})$ was collected in vacuum blood collection tubes with EDTA (0.05 M). The whole blood samples were stored at $4^{\circ} \mathrm{C}$.

RNA isolation. Total RNA was collected using an RNA extraction kit for whole blood (Ezol kit, Suzhou GenePharma Co., Ltd.) according to the manufacturer's protocol. RNA purity was determined through the measurement of absorbance using a 96-well plate (Corning Incorporated, Corning, NY, USA) (A) at 260, 280, and $230 \mathrm{~nm}$ with NanoDrop 2000 (Thermo Fisher Scientific, Inc., Waltham, MA, USA) (24). RNA concentration was determined from the A260. Qualifying samples were used to detect HER-2 expression by one-step RT-qPCR.

One-step RT-qPCR. HER-2 levels were measured using one-step HER-2 TaqMan RT-qPCR kits (Suzhou GenePharma Co., Ltd.), the fluorophore (SYBR Green) was purchased from Thermo Fisher Scientific, Inc. Reactions contained $2.5 \mu \mathrm{l}$ 10x PCR buffer, $2.5 \mu \mathrm{l}$ 5x RT buffer, $0.375 \mu \mathrm{l}$ of each primer, $0.5 \mu \mathrm{l}$ of each probe, $0.5 \mu \mathrm{l}$ enzyme mix, and $8 \mu \mathrm{l}$ blood RNA extract in $20 \mu \mathrm{l}$. Total RNA from MDA-MB-231 cells (from the American Type Culture Collection, Manassas, VA, USA) were used as the negative control. RT-qPCR cycling was performed on an ABI-Step One Plus system (Thermo Fisher Scientific, Inc.) as follows: $45^{\circ} \mathrm{C}$ for $5 \mathrm{~min}, 95^{\circ} \mathrm{C}$ for $30 \mathrm{sec}$, and 40 cycles of $5 \mathrm{sec}$ at $95^{\circ} \mathrm{C}$ and $50 \mathrm{sec}$ at $62^{\circ} \mathrm{C}$. Fluorogenic signals were detected at the end of the annealing-extension steps. A threshold was automatically set and the threshold 
Table I. Patient clinical and pathological characteristics.

\begin{tabular}{|c|c|c|c|c|c|c|c|c|c|}
\hline \multirow[b]{2}{*}{ Parameter } & \multicolumn{3}{|c|}{ All patients } & \multicolumn{2}{|c|}{$\begin{array}{l}\text { HER-2 mRNA } \\
\text { positive }\end{array}$} & \multicolumn{3}{|c|}{$\begin{array}{c}\text { HER-2 mRNA } \\
\text { negative }\end{array}$} & \multirow{2}{*}{$\begin{array}{l}\begin{array}{l}\text { HER-2 } \\
\text { value }\end{array} \\
\text { P-value }\end{array}$} \\
\hline & $\mathrm{n}$ & & $\%$ & $\mathrm{n}$ & $\%$ & $\mathrm{n}$ & & $\%$ & \\
\hline Patients enrolled & 70 & & $100 \%$ & 22 & 31.4 & 48 & & 68.6 & \\
\hline Age years (median) range) & & $52(27-82)$ & & & $51(30-66)$ & & $53(27-82)$ & & 0.131 \\
\hline Menopausal status & & & & & & & & & 0.114 \\
\hline Premenopausal & 36 & & 51.4 & 12 & 17.1 & 24 & & 34.3 & \\
\hline Postmenopausal & 34 & & 48.6 & 10 & 14.3 & 24 & & 34.3 & \\
\hline Stage & & & & & & & & & 0.367 \\
\hline I & 17 & & 24.3 & 9 & 12.9 & 8 & & 11.4 & \\
\hline II & 29 & & 41.4 & 5 & 7.1 & 24 & & 34.3 & \\
\hline III & 15 & & 21.4 & 5 & 7.1 & 10 & & 14.3 & \\
\hline Unknown & 9 & & 12.9 & 3 & 4.3 & 6 & & 8.6 & \\
\hline Tumor grade & & & & & & & & & 0.666 \\
\hline $\mathrm{I} / \mathrm{II}$ & 52 & & 74.3 & 16 & 22.9 & 36 & & 51.4 & \\
\hline III & 7 & & 10.0 & 2 & 2.9 & 5 & & 7.1 & \\
\hline Unknown & 11 & & 15.7 & 4 & 5.7 & 7 & & 10.0 & \\
\hline Tumor size $(\mathrm{cm})$ & & & & & & & & & 0.663 \\
\hline $1(2 \geq \mathrm{T} 1)$ & 30 & & 42.9 & 10 & 14.3 & 20 & & 28.6 & \\
\hline $2(2<\mathrm{T} 2<5)$ & 38 & & 54.3 & 11 & 15.7 & 27 & & 38.6 & \\
\hline $3(5 \leq \mathrm{T} 3)$ & 2 & & 2.8 & 1 & 1.4 & 1 & & 1.4 & \\
\hline Lymph node status & & & & & & & & & 0.860 \\
\hline 0 & 29 & & 41.4 & 10 & 14.3 & 19 & & 27.1 & \\
\hline $1-3$ & 20 & & 28.6 & 5 & 7.1 & 15 & & 21.4 & \\
\hline $4-9$ & 11 & & 15.7 & 3 & 4.3 & 8 & & 11.4 & \\
\hline$\geq 10$ & 4 & & 5.7 & 2 & 2.9 & 2 & & 2.9 & \\
\hline Unknown & 6 & & 8.6 & 2 & 2.9 & 4 & & 5.7 & \\
\hline Lymphovascular Invasion & & & & & & & & & $0.035^{\mathrm{a}}$ \\
\hline No & 37 & & 52.9 & 9 & 12.9 & 28 & & 40.0 & \\
\hline Yes & 19 & & 27.1 & 8 & 11.5 & 11 & & 15.7 & \\
\hline Unknown & 14 & & 20.0 & 5 & 7.1 & 9 & & 12.8 & \\
\hline Perineural Invasion & & & & & & & & & 0.506 \\
\hline No & 43 & & 61.4 & 9 & 12.8 & 34 & & 48.7 & \\
\hline Yes & 7 & & 10.0 & 4 & 5.7 & 3 & & 4.3 & \\
\hline Unknown & 20 & & 28.6 & 9 & 12.8 & 11 & & 15.7 & \\
\hline ER & & & & & & & & & 0.526 \\
\hline Negative & 21 & & 30.0 & 5 & 7.1 & 16 & & 22.9 & \\
\hline Positive & 49 & & 70.0 & 17 & 24.3 & 32 & & 45.7 & \\
\hline PR & & & & & & & & & 0.748 \\
\hline Negative & 32 & & 45.7 & 6 & 8.6 & 26 & & 37.1 & \\
\hline Positive & 38 & & 54.3 & 16 & 22.9 & 22 & & 31.4 & \\
\hline Ki-67 & & & & & & & & & $0.007^{\mathrm{a}}$ \\
\hline$\leq 14$ & 16 & & 22.9 & 5 & 7.1 & 11 & & 15.7 & \\
\hline$>14$ & 54 & & 77.1 & 17 & 24.3 & 37 & & 52.9 & \\
\hline Sub-type & & & & & & & & & 0.148 \\
\hline Luminal A & 10 & & 14.3 & 5 & 7.1 & 5 & & 7.1 & \\
\hline Luminal B & 39 & & 55.7 & 12 & 17.1 & 27 & & 38.6 & \\
\hline ERBB 2+ & 10 & & 14.3 & 0 & 0.0 & 10 & & 14.3 & \\
\hline Basal-like & 11 & & 15.7 & 5 & 7.1 & 6 & & 8.6 & \\
\hline HER-2 & & & & & & & & & $0.039^{\mathrm{a}}$ \\
\hline Negative & 50 & & 71.4 & 21 & 30.0 & 29 & & 41.4 & \\
\hline Positive & 20 & & 28.6 & 1 & 1.4 & 19 & & 21.7 & \\
\hline
\end{tabular}

${ }^{\mathrm{a}} \mathrm{P}<0.05$. HER-2, human epidermal growth factor receptor 2. HER-2, human epidermal growth factor receptor 2; ER, estrogen receptor; Progesterone receptor, PR; ERBB2, Erb-B2 Receptor Tyrosine Kinase 2. 
cycle value $(\mathrm{Cq})$ was determined $(25,26)$. Two replicate assays within and between runs were performed. The sequences of the primers used for HER-2 were as follows: Forward, 5'-CCA GCTGGCTCTCACACTG-3'; and reverse, 5'-AGCCCTTAC ACATCGGAGAAC-3'; probe, 5'-FAM/AGGCCCGAGAGC GGTTGGTGT/BHQ1-3'. Sequences of the primers used for $\beta$-actin were as follows: Forward, 5'-GACCCAGATCATGTT TGAGACCTT-3'; and reverse, 5'-CCATCACGATGCCAG TGGTA-3'; probe, 5'-FAMCCATGTACGTTGCTATCCAGG CTGTGCBHQ1-3'.

Sensitivity evaluation of HER-2 mRNA RT-qPCR. To test the sensitivity of HER-2 detection by RT-qPCR on blood samples, the SKBR-3 cell line (ATCC), which expresses high levels of HER-2, was 10-fold serially diluted with PBS ( $\mathrm{pH}$ 7.4) from $1 \times 10^{5}$ cells $/ \mathrm{ml}$ to $1 \mathrm{cell} / \mathrm{ml}$ using fluorescence-activated cell sorting (FACS; BD FACSARIA II; BD Biosciences, Franklin Lakes, NJ, USA) and spiked into $5 \mathrm{ml}$ normal blood (27). Following RNA extraction, HER-2 mRNA RT-qPCR was performed in duplicate.

Immunohistochemistry (IHC) and fluorescence in situ hybridization (FISH). Immunohistochemistry was performed according to previously described methods using a normal light microscope (magnification, x400) (28). Paraffin-embedded tissues from surgery were deparaffinized and pretreated in a microwave. The slides were incubated using monoclonal mouse anti-HER2 antibodies (1:200, Proteintech 60311-1-lg, China) for $1 \mathrm{~h}$ at $37^{\circ} \mathrm{C}$. After rinsing with PBS ( $\mathrm{pH}$ 7.4), sections were treated with a horseradish peroxidase conjugated-goat-anti-mouse secondary antibody $(1: 2,000$, Jackson ImmunoResearch, Inc., West Grove, PA, USA; cat no. 115-035-003) at room temperature for $1 \mathrm{~h}$. Then, the slides were incubated with 3-diaminobenzidine solution for $20 \mathrm{~min}$ at room temperature. Patients with HER2+ breast cancer was diagnosed by FISH in the Second Affiliated Hospital of Soochow University as described previously (22).

Cutoff value determination. To determine the cutoff value for HER-2, a total of 35 normal blood and 70 blood samples from breast cancer patients prior to surgery were collected and sorted by FACS (27). MB-MDA-231 and SKBR-3 cells $\left(1 \times 10^{0}, 1 \times 10^{1}\right.$, $1 \times 10^{2}, 1 \times 10^{3}$, and $10^{4}$ ) were spiked into $5 \mathrm{ml}$ normal blood. Samples were analyzed using the TaqMan HER-2 RT-qPCR kits (Suzhou GenePharma Co., Ltd). For each sample, $\mathrm{Ct}$ values for HER-2 were normalized to the $\mathrm{Ct}$ values of $\beta$-actin as an endogenous control to yield $\Delta \mathrm{Ct}$ data. For all of the 70 breast cancer blood samples and cell line-spiked samples, $\Delta \mathrm{Ct}$ values were normalized to the median $\Delta \mathrm{Ct}$ values of the 35 normal blood samples to obtain $\Delta \Delta \mathrm{Ct}$ data. HER-2 relative expression for each sample was calculated using the $2^{-\Delta \Delta C t}$ formula $(26,28)$.

Statistical analysis. Statistical analyses were performed using Statistical Package for Social Sciences software version 22 for Windows (IBM Corp., Armonk, NY, USA) and GraphPad Prism 6.01 (GraphPad Software, Inc., La Jolla, CA, USA). One-way analysis of variance (ANOVA), followed by Tukey's multiple comparison test by using GraphPad Prism 6.01 (GraphPad Software, Inc., La Jolla, CA, USA) to compare

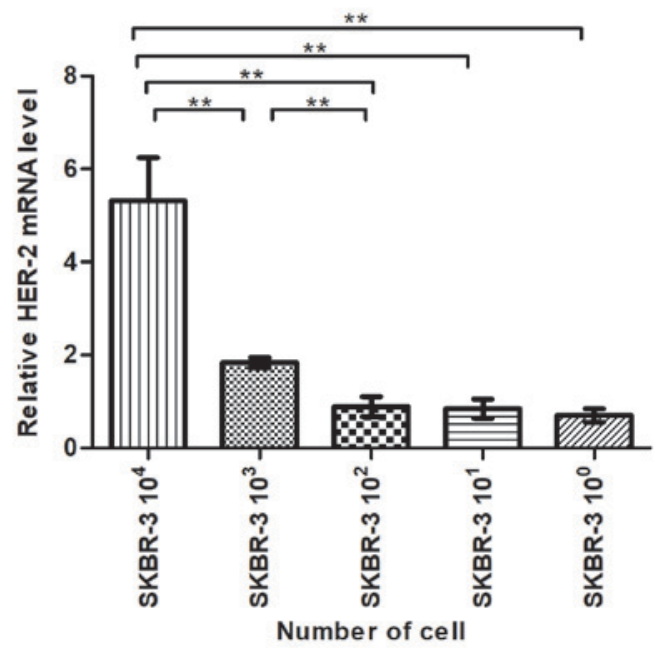

Figure 1. Evaluation of the HER-2 mRNA detection sensitivity of RT-qPCR. Relative expression values from serially diluted SKBR-3 cells are shown. The mean relative values were determined by RT-qPCR (one ANOVA, Tukey's Test, $\left.{ }^{* *} \mathrm{P}<0.01\right)$. RT-qPCR, reverse transcription-quantitative polymerase chain reaction.

the HER-2 mRNA levels in cell lines, peripheral blood and tissues. The Pearson $\chi^{2}$ test was used to assess the associations between blood HER-2 status and clinical features. The Wilcoxon signed rank test was performed to examine the mean changes in paired samples. Receiver operating characteristic (ROC) curve analysis was performed to determine the relationship between the HER-2 mRNA level in blood samples, and the HER-2 FISH and IHC status of primary tumor tissues. Sensitivity, specificity, and Youden index values were calculated to assess the diagnostic performance of RT-qPCR for determining HER-2 status. HER-2 expression curves representative of measurements taken during neoadjuvant chemotherapy were compared with changes in tumor size. Cohen's Kappa coefficient and 95\% confidence intervals (CI) were calculated to assess the agreement in HER-2 status between primary tumors and peripheral blood. All data are presented as the mean \pm standard error. $\mathrm{P}<0.05$ was considered to indicate a statistically significant difference.

\section{Results}

Sensitivity evaluation of RT-qPCR detection of HER-2 $m R N A$. The relative values obtained using serially diluted SKBR-3 cells are shown in Fig. 1. The mean relative RT-qPCR values obtained using $1 \times 10^{4}, 1 \times 10^{3}, 1 \times 10^{2}, 1 \times 10^{1}$, and $1 \times 10^{0}$ cells $/ \mathrm{ml}$ were $5.32,1.84,0.89,0.84$, and 0.70 , respectively; the results indicated that the relative $\mathrm{Ct}$ values of RT-qPCR decreased with a decreasing cell number. Therefore, it was determined that RT-qPCR demonstrated good sensitivity for the detection of HER-2 mRNA. Ct values from blank control reactions were negative for all experiments.

Peripheral blood HER-2 $\mathrm{mRNA}$ in preoperative patients and controls. Peripheral blood HER-2 mRNA status in samples from 70 preoperative patients and 35 healthy controls were determined by RT-qPCR. Tumor samples were HER-2-positive 


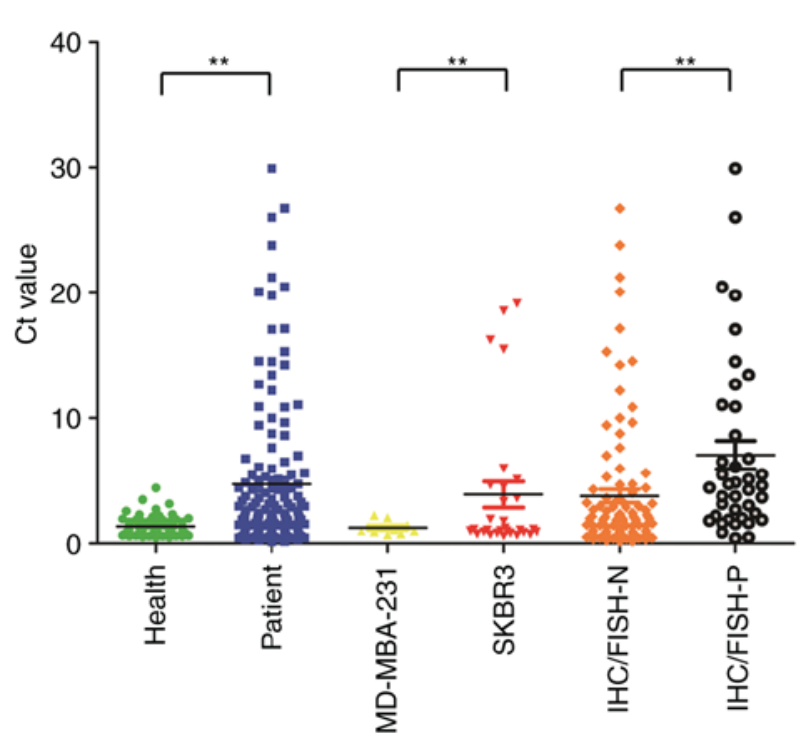

Figure 2. HER-2 mRNA expression in the different groups. MD-MBA-231: HER-2-negative breast cancer cell line. SKBR3: HER-2-positive breast cancer cell line. HER-2, human epidermal growth factor receptor 2; IHC, Immunohistochemistry; FISH, fluorescent in situ hybridization; IHC/FISH-N: HER-2-negative tissue as determined by IHC/FISH. IHC/FISH-P: HER-2-positive tissue as determined by IHC/FISH (one ANOVA, Tukey's Test, ${ }^{* *} \mathrm{P}<0.01$ ).

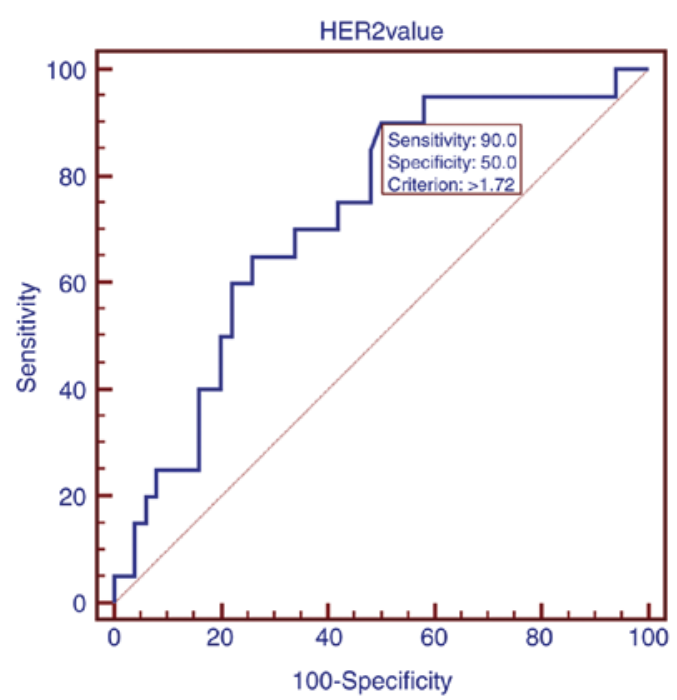

Figure 3. Comparison with HER-2 status determined by IHC/FISH in tumor tissue samples as a standard. AUC value: $0.723(\mathrm{P}<0.001)$. The optimized cutoff for peripheral blood with HER-2 mRNA positivity from preoperative patients was 1.72 , with $90 \%$ sensitivity, $50 \%$ specificity, and a Youden index value of 0.40 for the distinguishing of HER-2 negative and positive tumors by one-step RT-qPCR compared with IHC/FISH. HER-2, human epidermal growth factor receptor 2; AUC, area under the curve; IHC, Immunohistochemistry; FISH, fluorescent in situ hybridization; RT-qPCR, reverse transcription-quantitative polymerase chain reaction.

in $20(28.6 \%)$ patients and negative in $50(71.4 \%)$ patients when analyzed by IHC and/or FISH (14,22,28-30).

The upper $95 \%$ CI value for normal blood was 1.512 , which was set as the cutoff for the system analysis based on the $2^{-\Delta \Delta C t}$ method $(19,26,31)$. The system could distinguish tumor blood from normal blood, and tumor cells with high HER-2 expression from cells with low expression. The median values
Table II. Change of HER-2 mRNA level in patients pre- and postoperative based on cutoff of 1.512.

\begin{tabular}{|c|c|c|c|c|}
\hline \multirow{3}{*}{$\begin{array}{l}\text { HER-2 mRNA } \\
\text { (Preoperative) }\end{array}$} & \multicolumn{4}{|c|}{ HER-2 mRNA (Postoperative) } \\
\hline & \multicolumn{2}{|c|}{ Negative } & \multicolumn{2}{|c|}{ Positive } \\
\hline & $\mathrm{n}$ & $\%$ & $\mathrm{n}$ & $\%$ \\
\hline Negative $(n=6)$ & 2 & 33.3 & 4 & 66.7 \\
\hline Positive (n=7) & 2 & 28.6 & 5 & 71.4 \\
\hline
\end{tabular}

for the relative HER-2 mRNA level were 4.52 (0.39-29.92) for HER-2-positive, 1.89 (0.14-26.71) for HER-2-negative, and $1.12(0.48-4.41)$ for healthy control samples $(\mathrm{P}<0.0001$, one-way ANOVA; Fig. 2). Significant differences were observed between the peripheral blood samples with positive HER-2 mRNA expression from healthy controls and that from samples patients with from HER-2-positive $(\mathrm{n}=22, \mathrm{P}<0.001$, one-way ANOVA) or HER-2-negative ( $\mathrm{n}=48, \mathrm{P}<0.001$, one-way ANOVA) tumor samples. Significant differences were observed between the patients with HER-2 mRNA-positive peripheral blood and those with HER-2-positive tissue $(\mathrm{P}<0.001)$, and between the peripheral blood from subjects with HER-2 negative tissue or samples before operation from preoperative patients with breast cancer $(\mathrm{P}<0.05)$. No significant differences were observed between HER-2 mRNA-positive and HER-2 mRNA-negative peripheral blood from patients prior to surgery $(\mathrm{P}>0.05)$.

Comparison with HER-2 status determined by IHC/FISH in tumor tissue samples as a standard. HER-2 mRNA level in blood was correlated with HER-2 status in primary tumor tissue samples $\left(\mathrm{P}<0.05\right.$, Pearson $\chi^{2}$ test). Blood HER- 2 mRNA level in patients with breast cancer and HER-2 status determined by IHC/FISH in tumor tissues was used to produce an ROC curve (Fig. 3), for which the area under the curve (AUC) was $0.723(\mathrm{P}<0.001)$. Based on the ROC curves, the optimized cutoff for peripheral blood HER-2 mRNA positivity in preoperative patients was 1.72 , with $90 \%$ sensitivity, $50 \%$ specificity, and a Youden index value of 0.40 for one-step RT-qPCR distinguishing HER-2-negative and -positive tumors compared with IHC/FISH.

Combined pre-and postoperative analysis of HER-2 $m R N A$. The cutoff value for HER-2 mRNA positivity in circulating blood was $1.512(\mathrm{P}<0.0001)$. Five patients exhibited a positive peripheral blood HER-2 mRNA status prior to and following surgery (pre+/post+), while 2 were pre+/post-, 4 were pre-/post+, and 2 were pre-/post- (Table II). Thus, only 2 patients demonstrated a postoperative decrease in peripheral blood HER-2 mRNA, whereas 11 exhibited an HER-2 mRNA level that did not decrease.

Circulating HER-2 mRNA is a prognostic biomarker in patients receiving neoadjuvant chemotherapy. To analyze the effect of neoadjuvant chemotherapy on HER-2 mRNA expression in peripheral blood, the blood from five breast cancer patients 
Patient 1

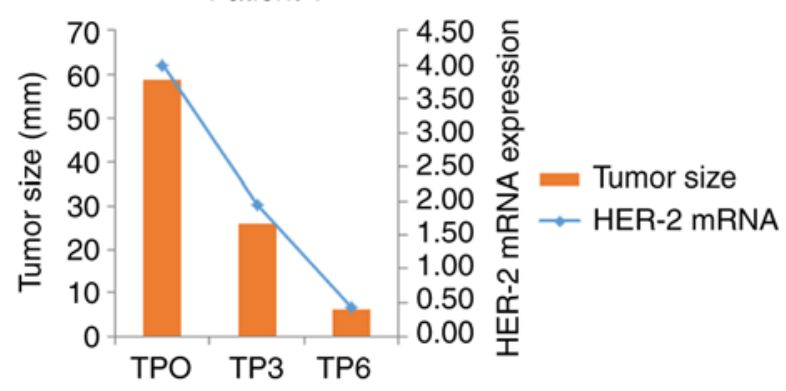

Patient 3

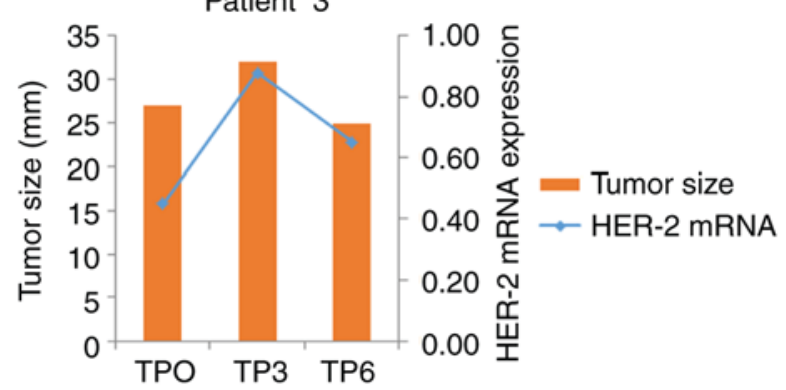

Patient 2

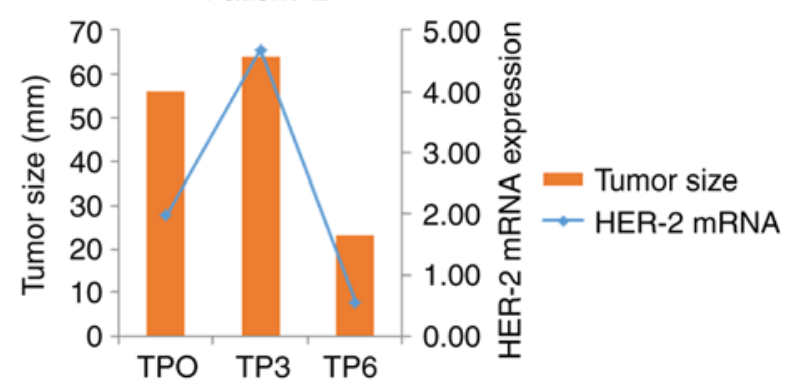

Patient 4

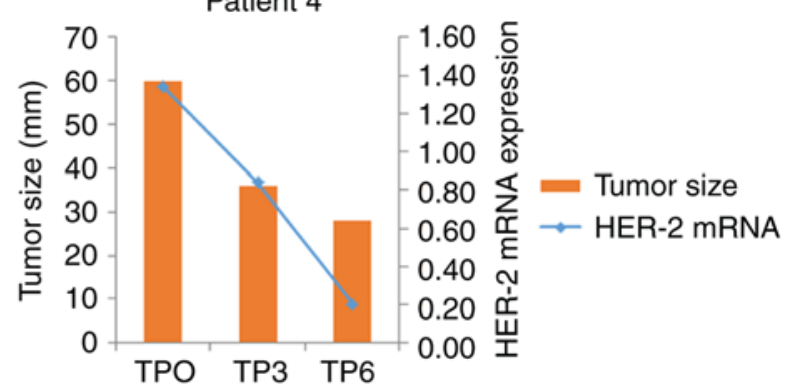

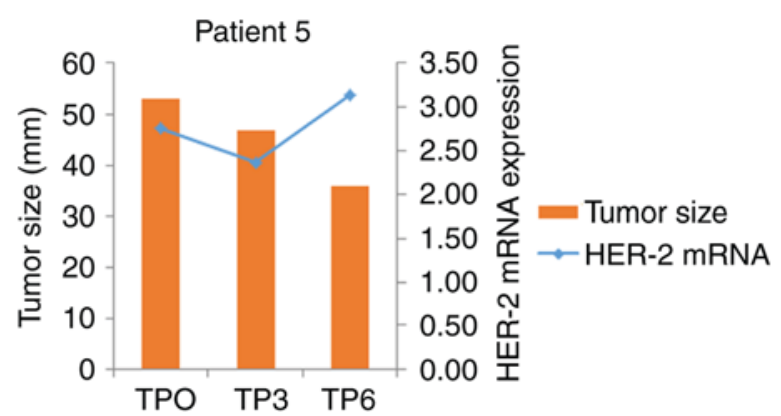

Figure 4. Circulating HER-2 mRNA expression is a prognostic biomarker for patients receiving neoadjuvant treatment. Patients received three cycles of 5-FU/epirubicin/cyclophosphamide with three sequential cycles of docetaxel and the diameter of the tumor was measured. HER-2, human epidermal growth factor receptor $2 \mathrm{TP}$, time point. $\mathrm{n}=5$.

was monitored during neoadjuvant therapy $(\mathrm{n}=5)$. All patients received three cycles of 5-FU/epirubicin/cyclophosphamide with three sequential cycles of docetaxel $(22,32)$. According to the treatment cycles, blood samples were divided into groups as follows: prior to antitumor treatment (time point zero; TP0), three treatment cycles (TP3), and six treatment cycles (TP6). Patients receiving neoadjuvant therapy were regularly monitored by MRI to evaluate treatment efficacy (32). In all patients who received neoadjuvant treatment, peripheral blood HER-2 mRNA and the original tumor size decreased (Fig. 4). This result suggests that the change in circulating HER-2 mRNA following neoadjuvant therapy was consistent with the results of imaging evaluation.

\section{Discussion}

Breast cancer is a highly heterogeneous malignant tumor, and HER-2 status changes during tumor progression, though these changes may not be detected in primary tumor histological examinations (33). Postoperative chemotherapy, endocrine therapy, and targeted therapy have been demonstrated to affect HER-2 expression (34). In clinical practice, the principal methods currently used to determine HER-2 tissue status are IHC and FISH, which can be used to assess HER-2 status at the time of diagnosis (35). In patients with metastatic breast cancer, biopsy samples for the metastases are not always available; furthermore, as breast cancer is highly heterogeneous and core needle biopsy (CNB) assesses only part of the tumor tissue, it may provide incomplete information for the diagnosis of metastatic breast cancer (36). Liquid biopsies can detect the HER-2 released into the peripheral blood from tumor tissues, even in patients with multiple tumor foci. Liquid biopsies also allow the detection of cancer-associated alleles in the blood and provide a genetic landscape for primary and metastatic tumors $(16,37)$. A liquid biopsy detects all circulating HER-2 mRNA released by breast tumors, and can be used for quantification by RT-qPCR $(31,38)$. Therefore, liquid biopsy results may be useful complementary information to the information obtained by histology. Furthermore, liquid biopsies can dynamically monitor changes in HER-2 levels in breast cancer following chemotherapy or targeted therapy, which provides prognostic information for clinical decisions (39).

HER-2 status in the peripheral blood can be converted from positive to negative following anti-HER-2 treatment in patients presenting with HER-2 positive primary tumor tissue, and these changes determine whether anti-HER-2 treatment should be continued (40). Koumarianou et al (41) demonstrated 
that certain patients with breast cancer with HER-2 negative tissue benefited from treatment with trastuzumab. Therefore, liquid biopsies may be more convenient and accurate than CNB biopsy for tumor monitoring (42).

In the present study, a suitable cutoff for circulating HER-2 mRNA was established based on the circulating HER-2 mRNA levels in healthy controls (22 positive and 48 negative). The cutoff for circulating blood HER-2 was 1.512 (19). In previous studies, Savino et al (19) and Korantizis et al (20) have described that the circulating levels of HER-2 were associated with the HER-2 mRNA level of tissues. The results of the RT-qPCR analysis were correlated with those of tissue HER-2 status determined by IHC and/or FISH, though there was a deviation of $\sim 4 \%$. Compared with previous study, Savino et al (19) performed qPCR to detect peripheral blood HER-2 expression from 30 HER-2 positve breast cancer patients (IHC) $(19,43)$. After establishing a cut-off value, 18 out of the 30 HER-2 positive patients were scored, indicating $\sim 40 \%$ deviation (14). These two results indicated circulating HER-2 is a potential diagnostic marker although there were some differences observed, which may be derived from using a different patient cohort. It is established that although IHC pathology is conveys a high degree of accuracy, the results are not definitive and are open to interpretation $(44,45)$. Therefore, the present study highlighted that HER-2 mRNA in peripheral blood may be an effective complementary assay in clinical practice. The prospective detection of HER-2 mRNA using one-step RT-qPCR on peripheral blood samples from patients with breast cancer prior to surgery or during treatment detected a significant difference in peripheral blood HER-2 mRNA level between normal samples and samples from breast cancer patients $(\mathrm{P}<0.0001)$. Xu et al (46) previously identified that $\sim 43.3 \%$ of patients with breast cancer were positive for plasma HER-2 mRNA, whereas only $10 \%$ were positive in the control group $(\mathrm{P}<0.001)$. Oloomi et al (47) obtained similar results, with HER-2 positivity detected in $36.7 \%$ of patients with breast cancer, and reported significant differences between patients and healthy controls $(\mathrm{P}<0.05)$. However, Owrangi et al (21), indicated that there were no differences in the expression of HER2 in patients with cancer compared with healthy individuals, which may be a result of a different patient sample. Collectively these studies indicate that peripheral blood HER-2 mRNA is higher in breast cancer samples than in samples from patients without cancer, indicating that HER-2 mRNA in blood may be a dependable biomarker for identifying patients with breast cancer irrespective of the HER-2 status of the primary tumor. However, the exact level of circulating HER-2 mRNA in peripheral blood that identifies breast cancer, especially HER-2-positive cancer, was not determined in these studies.

The present study also identified an association between the level of HER-2 mRNA in blood and HER-2 tissue status $(\mathrm{P}<0.05)$ with high sensitivity and low specificity; the agreement between blood HER-2 mRNA detected by one-step RT-qPCR and tissue HER-2 status determined by IHC/FISH was $30.4 \%$ ( $\mathrm{P}<0.01$, Kappa coefficient). These results suggest that the detection of circulating HER-2 mRNA may be a useful predictive method for breast cancer diagnosis, complementary to tissue analysis. However, a previous study identified no correlation between blood HER-2 mRNA level and tissue HER-2 status (48). Additionally, no associations were observed between the blood HER-2 mRNA level, and the lymph node status, tumor grade, tumor stage, tumor size, patient age, menopausal status, or ER or PR status of the primary tumor in a previous study (49). Furthermore, the association between the level of HER-2 mRNA in blood and Ki-67 expression or the lymphovascular invasion status of primary tumors $(\mathrm{P}<0.01$ and $\mathrm{P}<0.05$, respectively) indicated a poor prognosis. The discrepancy in HER-2 status between peripheral blood and tissue could be attributed to differences in the two techniques, and the heterogeneity of breast cancer. No association was observed between peripheral blood HER-2 mRNA and other prognostic factors.

Information on peripheral HER-2 mRNA levels for predicting the efficacy of antitumor treatment in breast cancer is limited. In the present study, changes in HER-2 mRNA during neoadjuvant therapy were evaluated. Peripheral blood HER-2 mRNA in breast cancer patients was monitored during neoadjuvant therapy to correlate circulating HER-2 mRNA levels with therapeutic efficacy. The changes in circulating HER-2 mRNA during treatment were consistent with the results of MRI evaluation. As depicted in Fig. 4, all patients receiving neoadjuvant chemotherapy exhibited a decrease in circulating HER-2 mRNA after antitumor treatment, excluding patient 5 . However, these results were opposite with the prognostic value of peripheral blood HER-2 mRNA detection during antitumor treatment using Docetaxel which may resulted from different patient cohort (20). The discrepancy between peripheral blood HER-2 mRNA level and tumor size after antitumor treatment in these patients may be attributed to differences in therapeutic responses and the heterogeneity of breast cancer. The detection of circulating HER-2 mRNA in patients receiving neoadjuvant chemotherapy suggested that patients benefited from neoadjuvant therapy for the treatment of breast cancer, and that circulating HER-2 mRNA could be used to predict breast cancer progression. Thus, the results demonstrated that HER-2 mRNA in peripheral blood could be used as a prognostic biomarker during neoadjuvant or adjuvant treatment.

To conclude, the present study has provided evidence from a patient cohort for the diagnostic value of circulating HER-2 for breast cancer; meanwhile, the cut-off value of 1.512 (mean of $2^{-\Delta \Delta C t}$ ) was established which may be useful in clinical applications. Finally, five patients were analyzed and identified that circulating HER-2 was associated with the outcome of neoadjuvant chemotherapy, which may serve as a novel prognostic biomarker.

\section{Acknowledgements}

Not applicable.

\section{Funding}

This work was supported by grants from the Suzhou Health Planning Commission Key Clinical Diagnosis and Treatment Program (grant no. LCZX201606), the Soochow Science and Technology Project (grant no. SYS201631), and the Science, Education and Health Foundation of Soochow City 
(grant no. KJXW2014011). The project was also supported by the Second Affiliated Hospital of Soochow University's Preponderant Clinic Discipline Group Project Funding (grant no. XKQ2015008).

\section{Availability of data and materials}

All data generated or analyzed during this study are included in this published article.

\section{Authors' contributions}

YW and QM performed the experiments, analyzed the data and wrote the manuscript. ZY, LS, JW, JR, BL, DX, RH, PZ provided technical assistance, analyzed the data and modified the manuscript. GJ designed and supervised the study. All authors are in agreement with the content of the manuscript.

\section{Ethics approval and consent to participate}

Study approval was obtained from the independent ethics committee at the Second Affiliated Hospital of Soochow University (Suzhou, China). The privacy of the patients involved was protected. Patients provided written informed consent.

\section{Patient consent for publication}

Study participants provided consent for the publication of the data and any associated images.

\section{Competing interests}

This study uses equipment from Shanghai GenePharma Co., Ltd. (Shanghai, China).

\section{References}

1. Fan L, Strasser-Weippl K, Li JJ, St Louis J, Finkelstein DM, $\mathrm{Yu} \mathrm{KD}$, Chen WQ, Shao ZM and Goss PE: Breast cancer in China. Lancet Oncol 15: e279-e289, 2014.

2. DeSantis CE, Ma J, Goding Sauer A, Newman LA and Jemal A: Breast cancer statistics, 2017, racial disparity in mortality by state. CA Cancer J Clin 67: 439-448, 2017.

3. Slamon D, Clark G, Wong S, Levin W, Ullrich A and McGuire W: Human breast cancer: Correlation of relapse and survival with amplification of the HER-2/neu oncogene. Science 235: 177-182, 1987.

4. Press MF, Bernstein L, Thomas PA, Meisner LF, Zhou JY, Ma Y, Hung G, Robinson RA, Harris C and El-Naggar A: HER-2/neu gene amplification characterized by fluorescence in situ hybridization: poor prognosis in node-negative breast carcinomas. J Clin Oncol 15: 2894-2904, 1997.

5. Olayioye MA, Neve RM, Lane HA and Hynes NE: The ErbB signaling network: Receptor heterodimerization in development and cancer. EMBO J 19: 3159-3167, 2000.

6. Dawood S, Broglio K, Buzdar AU, Hortobagyi GN and Giordano SH: Prognosis of women with metastatic breast cancer by HER 2 status and trastuzumab treatment: An institutional-based review. J Clin Oncol 28: 92-98, 2010.

7. Ross JS, Slodkowska EA, Symmans WF, Pusztai L, Ravdin PM and Hortobagyi GN: The HER-2 receptor and breast cancer: Ten years of targeted anti-HER-2 therapy and personalized medicine. Oncologist 14: 320-368, 2009.

8. Akiyama T, Sudo C, Ogawara H, Toyoshima K and Yamamoto T: The product of the human c-erbB-2 gene: A 185-kilodalton glycoprotein with tyrosine kinase activity. Science 232: 1644-1646, 1986.
9. Belengeanu A,MuresanA,StoicanescuDandLazarE:Amplification of HER-2 gene in breast cancer: Immunohistochemical and FISH assessment. Rom J Morphol Embryol 51: 321-326, 2010.

10. Piccart-Gebhart MJ, Procter M, Leyland-Jones B, Goldhirsch A, Untch M, Smith I, Gianni L, Baselga J, Bell R, Jackisch C, et al: Trastuzumab after adjuvant chemotherapy in HER2-positive breast cancer. N Engl J Med 353: 1659-1672, 2005.

11. Smith I, Procter M, Gelber RD, Guillaume S, Feyereislova A, Dowsett M, Goldhirsch A, Untch M, Mariani G, Baselga J, et al: 2-year follow-up of trastuzumab after adjuvant chemotherapy in HER2-positive breast cancer: A randomised controlled trial. Lancet 369: 29-36, 2007.

12. Rugo HS, Li H and Gui X: Strategies and progress of endocrine therapy for patients with metastatic breast cancer. Adv Exp Med Biol 1026: 403-418, 2017.

13. Gianni L, Bisagni G, Colleoni M, Del Mastro L, Zamagni C, Mansutti M,Zambetti M,Frassoldati A, De Fato R, Valagussa P and Viale G: Neoadjuvant treatment with trastuzumab and pertuzumab plus palbociclib and fulvestrant in HER2-positive, ER-positive breast cancer (NA-PHER2): An exploratory, open-label, phase 2 study. Lancet Oncol 19: 249-256, 2018.

14. Brugmann A, Lelkaitis G, Nielsen S, Jensen KG and Jensen V: Testing HER2 in breast cancer: A comparative study on BRISH, FISH and IHC. Appl Immunohistochem Mol Morphol 19: 203-211, 2011.

15. Wolff AC, Hammond ME, Hicks DG, Dowsett M, McShane LM, Allison KH, Allred DC, Bartlett JM, Bilous M, Fitzgibbons P, et al: Recommendations for human epidermal growth factor receptor 2 testing in breast cancer: American Society of Clinical Oncology/College of American Pathologists clinical practice guideline update. J Clin Oncol 31: 3997-4013, 2013.

16. De Mattos-Arruda L: Liquid biopsy for HER2-positive breast cancer brain metastasis: The role of the cerebrospinal fluid. ESMO Open 2: e000270, 2017.

17. Apostolaki S, Perraki M, Kallergi G, Kafousi M, Papadopoulos S, Kotsakis A, Pallis A, Xenidis N, Kalmanti L, Kalbakis K, et al: Detection of occult HER2 mRNA-positive tumor cells in the peripheral blood of patients with operable breast cancer: Evaluation of their prognostic relevance. Breast Cancer Res Treat 117: 525-534, 2009.

18. Apostolaki S, Perraki M, Pallis A, Bozionelou V, Agelaki S, Kanellou P, Kotsakis A, Politaki E, Kalbakis K, Kalykaki A, et al: Circulating HER2 mRNA-positive cells in the peripheral blood of patients with stage I and II breast cancer after the administration of adjuvant chemotherapy: Evaluation of their clinical relevance. Ann Oncol 18: 851-858, 2007.

19. Savino M, Garrubba M, Parrella P, Baorda F, Copetti M, Murgo R, Zelante L, Carella M, Valori VM and Santini SA: Development of real-time quantitative reverse transcription-PCR for Her2 detection in peripheral blood from patients with breast cancer. Clin Chim Acta 384: 52-56, 2007.

20. Korantzis I, Kalogeras KT, Papaxoinis G, Kotoula V, Koutras A, Soupos N, Papakostas P, Dionysopoulos D, Samantas E, Christodoulou C, et al: Expression of angiogenic markers in the peripheral blood of patients with advanced breast cancer treated with weekly docetaxel. Anticancer Res 32: 4569-4580, 2012.

21. Owrangi B,Habibagahi M, Hosseini A,Haghighi NF, Mardani M, Talei A, Ghaderi A and Jaberipour M: MDM2, E-cadherin, Survivin and Her2 mRNA status in peripheral blood of patients with breast cancer. Mid East J Cancer 4, 2013.

22. Press MF, Sauter G, Buyse M, Fourmanoir H, Quinaux E, Tsao-Wei DD, Eiermann W, Robert N, Pienkowski T, Crown J, et al: HER2 gene amplification testing by fluorescent in situ hybridization (FISH): Comparison of the ASCO-College of American Pathologists Guidelines With fish scores used for enrollment in breast cancer international research group clinical trials. J Clin Oncol 34: 3518-3528, 2016.

23. Malzkorn B and Reifenberger G: Practical implications of integrated glioma classification according to the World Health Organization classification of tumors of the central nervous system. Curr Opin Oncol 28: 494-501, 2016, 2016.

24. Fleige S and Pfaffl MW: RNA integrity and the effect on the real-time qRT-PCR performance. Mol Aspects Med 27: 126-139, 2006.

25. El Hadi H, Abdellaoui-Maane I, Kottwitz D, El Amrani M, Bouchoutrouch N, Qmichou Z, Karkouri M, ElAttar H, Errihani H, Fernandez PL, et al: Development and evaluation of a novel RT-qPCR based test for the quantification of HER2 gene expression in breast cancer. Gene 605: 114-122, 2017. 
26. Livak KJ and Schmittgen TD: Analysis of relative gene expression data using real-time quantitative PCR and the 2(-Delta Delta C(T)) method. Methods 25: 402-408, 2001.

27. Leslie DS, Johnston WW, Daly L, Ring DB, Shpall EJ, Peters WP and Bast RC Jr: Detection of breast carcinoma cells in human bone marrow using fluorescence-activated cell sorting and conventional cytology. Ame J Clin Pathol 94: 8-13, 1990.

28. Catenacci DV, Liao WL, Zhao L, Whitcomb E, Henderson L, O'Day E, Xu P, Thyparambil S, Krizman D, Bengali K, et al: Mass-spectrometry-based quantitation of Her2 in gastroesophageal tumor tissue: Comparison to IHC and FISH. Gastric Cancer 19: 1066-1079, 2016.

29. Check W: IHC, FISH still sharing HER 2 spotlight. CAP Today 19: 1, 40, 42 passim, 2005.

30. Louis DN, Perry A, Reifenberger G, von Deimling A, Figarella-Branger D, Cavenee WK, Ohgaki H, Wiestler OD, Kleihues P and Ellison DW: The 2016 world health organization classification of tumors of the central nervous system: A summary. Acta Neuropathol 131: 803-820, 2016.

31. Caraguel CG, Stryhn H, Gagne N, Dohoo IR and Hammell KL: Selection of a cutoff value for real-time polymerase chain reaction results to fit a diagnostic purpose: Analytical and epidemiologic approaches. J Vet Diagn Invest 23: 2-15, 2011.

32. Jensen LR, Huuse EM, Bathen TF, Goa PE, Bofin AM, Pedersen TB, Lundgren S and Gribbestad IS: Assessment of early docetaxel response in an experimental model of human breast cancer using DCE-MRI, ex vivo HR MAS and in vivo $1 \mathrm{H}$ MRS. NMR Biomed 23: 56-65, 2010.

33. Zhao X, Rodland EA, Tibshirani R and Plevritis S: Molecular subtyping for clinically defined breast cancer subgroups. Breast Cancer Res 17: 29, 2015.

34. Yan J, Liu XL, Han LZ, Xiao G, Li NL, Deng YN, Yin LC, Ling LJ, Yu XY, Tan CL, et al: Relation between Ki-67, ER, PR, Her2/neu, p21, EGFR and TOP II- $\alpha$ expression in invasive ductal breast cancer patients and correlations with prognosis. Asian Pac J Cancer Prev 16: 823-829, 2015.

35. Tsuda H: HER-2 (c-erbB-2) test update: Present status and problems. Breast Cancer 13: 236-248, 2006.

36. Hall C, Valad L and Lucci A: Circulating tumor cells in breast cancer patients. Crit Rev Oncog 21: 125-139, 2016

37. Wang HY, Ahn S, Kim S, Park S, Jung D, Park S, Han H, Sohn J, Kim S and Lee H: Detection of circulating tumor cell-specific markers in breast cancer patients using the quantitative RT-PCR assay. Int J Clin Oncol 20: 878-890, 2015

38. Janjigian YY, Riches JC, Ku GY, Imatiaz T, Capanu M and Chou JF: Loss of human epidermal growth factor receptor 2 (HER2) expression in HER2-overexpressing esophagogastric (EG) tumors treated with trastuzumab. Gastrointesti Cancers Symposium, 2015.

39. Crowley E, Di Nicolantonio F, Loupakis F and Bardelli A: Liquid biopsy: Monitoring cancer-genetics in the blood. Nat Rev Clin Oncol 10: 472-484, 2013.
40. Raitoharju E, Seppala I, Oksala N, Lyytikäinen LP Raitakari O, Viikari J, Ala-Korpela M, Soininen P, Kangas AJ, Waldenberger M, et al: Blood microRNA profile associates with the levels of serum lipids and metabolites associated with glucose metabolism and insulin resistance and pinpoints pathways underlying metabolic syndrome: The cardiovascular risk in Young Finns Study. Mol Cell Endocrinol 391: 41-49, 2014.

41. Koumarianou A, Karayannopoulou G, Gourgioti G, Batistatou A, Bobos M, Efstratiou I, Miliaras D, Galani E, Pentheroudakis G, Pectasides D, et al: PAI-1 and HER2 interaction in advanced breast cancer disease: Evidence for added benefit from trastuzumab in HER2-negative patients. Cancer Chemother Pharmacol 75: 1289-1301, 2015.

42. Hudis CA: Biology before anatomy in early breast cancer-precisely the point. N Engl J Med 373: 2079-2080, 2015

43. Savino M, Parrella P, Copetti M, Barbano R, Murgo R, Fazio VM, Valori VM, Carella M, Garrubba M and Santini SA: Comparison between real-time quantitative PCR detection of HER 2 mRNA copy number in peripheral blood and ELISA of serum HER2 protein for determining HER2 status in breast cancer patients. Cell Oncol 31: 203-211,2009.

44. Al Diffalha S, Shaar M, Barkan GA, Wojcik EM, Picken MM and Pambuccian SE: Immunohistochemistry in the workup of prostate biopsies: Frequency, variation and appropriateness of use among pathologists practicing at an academic center. Ann Diagn Pathol 27: 34-42, 2017.

45. Allison KH: Molecular pathology of breast cancer: What a pathologist needs to know. Am J Clin Pathol 138: 770-780, 2012.

46. Xu Y, Yao L, Li H, Ouyang T, Li J, Wang T, Fan Z, Lin B, Lu Y, Larsson O and Xie Y: Presence of erbB2 mRNA in the plasma of breast cancer patients is associated with circulating tumor cells and negative estrogen and progesterone receptor status. Breast Cancer Res Treat 97: 49-55, 2006.

47. OloomiM,BouzariS, Mohagheghi MA andKhodayaran-TehraniH: Molecular markers in peripheral blood of Iranian women with breast cancer. Cancer Microenviron 6: 109-116, 2013.

48. Moazzezy N, Ebrahimi F, Sisakht MM, Yahyazadeh H, Bouzari S and Oloomi M: Relationship between erb-B2 mRNA expression in blood and tissue of invasive ductal carcinoma breast cancer patients and clinicopathological characteristics of the tumors. Asian Pac J Cancer Prev 17: 249-254, 2016.

49. Tse C, Brault D, Gligorov J, Antoine M, Neumann R, Lotz JP and Capeau J: Evaluation of the quantitative analytical methods real-time PCR for HER-2 gene quantification and ELISA of serum HER-2 protein and comparison with fluorescence in situ hybridization and immunohistochemistry for determining HER-2 status in breast cancer patients. Clin Chem 51: 1093-1101, 2005.

This work is licensed under a Creative Commons Attribution-NonCommercial-NoDerivatives 4.0 International (CC BY-NC-ND 4.0) License. 